ORIGINAL ARTICLE

\title{
Ventilation inhomogeneity in children with primary ciliary dyskinesia
}

\author{
Kent Green, ${ }^{1}$ Frederik F Buchvald, ${ }^{1}$ June Kehlet Marthin, ${ }^{1}$ Birgitte Hanel, ${ }^{1}$ \\ Per M Gustafsson, ${ }^{2}$ Kim Gjerum Nielsen ${ }^{1}$
}

\begin{abstract}
- Additional data are published online only. To view the file please visit the journal online (http://thorax.bmj.com/content/ 67/1.toc).

${ }^{1}$ Danish PCD Center and Pediatric Pulmonary Service, Department of Pediatrics, Copenhagen University Hospital, Copenhagen, Denmark ${ }^{2}$ Department of Pediatrics, Central Hospital, Skövde, Sweden
\end{abstract}

\section{Correspondence to} Dr Kim Gjerum Nielsen, Danish PCD Center and Pediatric Pulmonary Service, Department of Pediatrics, Copenhagen University Hospital, Blegdamsvej 9, DK-2100 Copenhagen, Denmark; kgn@dadlnet.dk

Received 1 July 2011 Accepted 5 September 2011 Published Online First 26 September 2011

\section{ABSTRACT}

Background The lung clearance index (LCI) derived from the multiple breath inert gas washout (MBW) test reflects global ventilation distribution inhomogeneity. It is more sensitive than forced expiratory volume in $1 \mathrm{~s}$ $\left(\mathrm{FEV}_{1}\right)$ for detecting abnormal airway function and correlates closely with structural lung damage in children with cystic fibrosis, which shares features with primary ciliary dyskinesia (PCD). Normalised phase III slope indices $S_{\text {cond }}$ and $S_{\text {acin }}$ reflect function of the small conducting and acinar airways, respectively. The involvement of the peripheral airways assessed by MBW tests has not been previously described in PCD.

Methods A cross-sectional MBW study was performed in 27 children and adolescents with verified PCD, all clinically stable and able to perform lung function tests. LCl, $S_{\text {cond }}(n=23)$ and $S_{\text {acin }}(n=23)$ were derived from MBW using a mass spectrometer and sulfur hexafluoride as inert marker gas. MBW indices were compared with present age, age at diagnosis and spirometry findings, and were related to published normative values.

Results $\mathrm{LCl} \mathrm{S}_{\text {cond }}$ and $\mathrm{S}_{\text {acin }}$ were abnormal in $85 \%, 96 \%$ and $78 \%$ of patients with PCD and in $81 \%, 93 \%$ and $79 \%$, respectively, of $13 / 27$ subjects with normal $\mathrm{FEV}_{1}$. LCl and $S_{\text {acin }}$ correlated significantly while $S_{\text {cond }}$ did not correlate with any other lung function parameters. None of the lung function measurements correlated with age or age at diagnosis.

Conclusions PCD is characterised by marked peripheral airway dysfunction. MBW seems promising in the early detection of lung damage, even in young patients with PCD. The relationship of MBW indices to the outcome of long-term disease and their role in the management of PCD need to be assessed.

\section{INTRODUCTION}

Primary ciliary dyskinesia (PCD) is a rare congenital disease characterised by defective ciliary function, which leads to impaired mucociliary clearance and consequently to recurrent and chronic upper and lower airway infections. ${ }^{12}$ Patients with PCD most often present with persistent rhinitis and chronic productive cough, but the heterogeneous nature of the disease makes early diagnosis difficult. ${ }^{3} \mathrm{~A}$ recently published longitudinal study from our centre suggested that PCD is a disease which seriously compromises lung function already at preschool age with a highly variable course of forced expiratory volume in $1 \mathrm{~s}\left(\mathrm{FEV}_{1}\right)$ and forced vital capacity (FVC) even after early diagnosis. ${ }^{4}$
However, traditional spirometry is mostly sensitive in detecting proximal airway disease, which may have limitations as early lung damage in PCD may be of peripheral origin. This is supported by a case report in which two of three patients with PCD who had infant pulmonary lung function performed demonstrated values suggestive of primary pathology in smaller peripheral airways. ${ }^{5}$

PCD lung disease shares several features with cystic fibrosis (CF): clinical findings include chronic productive cough and, although less frequent, colonisation by Pseudomonas aeruginosa (PA), ${ }^{6}$ and radiological changes include bronchiectasis, mucus plugging and peribronchial thickening. ${ }^{7}$ However, although data on early structural changes in PCD lung disease are lacking, it is reasonable to suggest that PCD may resemble CF in which initial lung damage has been shown to start in the peripheral airways. ${ }^{8}$ In CF, spirometry has traditionally been used to monitor lung function, but several studies have shown spirometry to be insensitive in tracking early progressive lung disease. ${ }^{9-12}$ The lung clearance index (LCI), derived from a multiple breath inert gas washout test (MBW), is a measure of global ventilation inhomogeneity (VI) and small airway dysfunction. LCI has been shown to detect lung damage in CF more readily than other pulmonary function tests ${ }^{913}$ and to be predictive of subsequent lung function when measured at preschool age. ${ }^{10}$ In addition, determination of concentration normalised phase III slope $\left(\mathrm{Sn}_{\text {III }}\right)$ indices allows assessment of VI arising in the small conductive airway zone $\left(\mathrm{S}_{\text {cond }}\right)$ and more peripherally close to or within the acinar airway zone $\left(\mathrm{S}_{\text {acin }}\right) .{ }^{14}$ Peripheral airway function assessed by LCI, $\mathrm{S}_{\text {cond }}$ and $\mathrm{S}_{\text {acin }}$ in children and adolescents with PCD has not been previously reported.

The aim of our study was to assess peripheral airway function in children and adolescents with PCD using MBW and to compare the findings with spirometry. We hypothesised that PCD lung disease is characterised by marked peripheral dysfunction, and that abnormal ventilation distribution is a frequent finding despite normal spirometry. Some of the study results have been previously reported in abstract form. ${ }^{15}$

\section{METHODS \\ Design of study}

This was a cross-sectional prospective study. All patients had lung function and $\mathrm{MBW}$ tests performed at their routine annual review at the National Danish PCD Center. Management is according to previous publications from the same centre. ${ }^{4}$ 


\section{Study patients}

Patients with a diagnosis of PCD aged $\leq 18$ years were eligible for the study. All patients had a consistent history of symptoms characteristic of $\mathrm{PCD},{ }^{16}{ }^{17}$ and basic tests to rule out CF and immunodeficiency were performed. Nasal nitric oxide measurement (nNO) was used as a preliminary screening test, although without necessarily excluding patients with a high suspicion of PCD. ${ }^{18}$ Furthermore, functional studies on ciliary beat pattern and frequency analysis using video recording and electron microscopy (EM) analysis of ciliary ultrastructure were key diagnostic tests. ${ }^{1}$ Functional studies were performed twice, at least one month apart. Patients had to be considered in a stable clinical condition on the day of MBW measurement.

\section{Measurements \\ MBW}

Tidal breathing sulfur hexafluoride $\left(\mathrm{SF}_{6}\right)$ washout was performed in all patients using a mass spectrometer (AMIS 2000, Innovision, Odense, Denmark) for gas analysis, as previously described. ${ }^{13}$ The LCI and the concentration normalised slope III indices $\left(\mathrm{S}_{\text {acin }}\right.$ and $\left.\mathrm{S}_{\text {cond }}\right)$ were calculated. LCI was calculated as the number of lung volume turnovers ( $\mathrm{TO}$; ie, the cumulative expired volume divided by the functional residual capacity, FRC) needed to lower the end-tidal tracer gas concentration to less than $1 / 40$ th of the starting concentration. ${ }^{13}$ The mean LCI result from three MBW measurements in each patient was used for analysis. The concentration normalised slope of phase III $\left(\mathrm{Sn}_{\text {III }}\right)$ for each subsequent breath during MBW was determined to calculate $S_{\text {cond }}$ and $S_{\text {acin }}$. The phase III slope was converted to $\mathrm{Sn}_{\text {III }}$ by dividing the slope by the mean gas concentration over the slope to allow for gas dilution. The $\mathrm{Sn}_{\text {III }}$ was further multiplied by tidal volume $(V T)$ giving the $\mathrm{Sn}_{\text {III }} \times$ VT in order to account for inter-individual differences in lung size and breathing pattern. ${ }^{19}$ The $\mathrm{Sn}_{\text {III }} \times$ VT was used in all subsequent analyses and is henceforth referred to as $\mathrm{Sn}_{\mathrm{III}}$ in this paper. For determination of $S_{\text {cond }}$ and $S_{\text {acin }}, \mathrm{Sn}_{\text {III }}$ and $\mathrm{TO}$ values for each subsequent breath from the three washouts were first averaged. For each breath, $\mathrm{Sn}_{\text {III }}$ was then plotted against the corresponding $\mathrm{TO}$ value. $\mathrm{S}_{\text {cond }}$ was defined as the rate of $\mathrm{Sn}_{\mathrm{III}}$ increase between TO 1.5 and 6.0. $S_{\text {acin }}$ was defined as the first breath $\mathrm{Sn}_{\text {III value }}$ minus the convection-dependent inhomogeneity contribution to this value (ie, $\mathrm{S}_{\text {cond }} \times \mathrm{TO}$ for the first breath). MBW results from this study were compared with data previously collected in healthy Swedish schoolchildren obtained using identical equipment, software and procedures. ${ }^{13} 20$ The authors performing and calculating the MBW tests have undergone training and been under continual supervision by the Swedish laboratory. Further technical details and reference values of the MBW technique are provided in the online supplement and elsewhere. ${ }^{20}$

\section{Spirometry}

Spirometry was performed according to ATS/ERS standards ${ }^{21}$ and $\mathrm{FEV}_{1}, \mathrm{FVC}$, forced expiratory flow at $25-75 \%$ of FVC $\left(\mathrm{FEF}_{25-75}\right)$ and $\mathrm{FEV}_{1} / \mathrm{FVC}$ ratio were recorded. The recently published 'all ages' reference equations were used. ${ }^{22}$ Abnormal lung function was defined as z-scores $<-1.96$.

\section{Statistical analysis}

Lung function was expressed as z-scores, which were calculated as (measured value - predicted value)/RSD from the reference population. ${ }^{22}$ The upper limit of normal (ULN) was defined as the predicted mean plus $1.96 \mathrm{RSD}$ for MBW variables and the lower limit of normal (LLN) as predicted mean minus 1.96 RSD for spirometry variables. MBW parameters were correlated to spirometry parameters, age and age at diagnosis using a linear regression model. A $p$ value of $<0.05$ was accepted as statistically significant. SAS V.9.2 (SAS Institute) was used for statistical analyses.

\section{RESULTS}

Twenty-seven patients with PCD from the National Danish PCD cohort were included in the study; all patients had LCI measurements performed. $\mathrm{Sn}_{\mathrm{III}}$ indices could not be calculated in four patients owing to irregular breathing patterns. In two patients spirometry was performed on a separate day because of technical problems and the dataset closest in time to the date of the MBW test ( 5 weeks later) was used instead. Both patients were clinically stable on the day spirometry was performed, and spirometry showed stable measurements over time.

Three patients did not have a conclusive abnormal ciliary beat pattern and frequency during the investigation. One had clinical signs and symptoms of PCD, situs inversus, hydrocephalus, repeated abnormal pulmonary radioaerosol mucociliary clearance tests, ${ }^{23}$ borderline abnormal nNO, low exhaled $\mathrm{NO}$ measurements $<5 \mathrm{ppb}$, but conflicting functional studies not certain of abnormal beat pattern and an EM without classical ultrastructural defects. Two other patients did not have a conclusive ciliary function test as they both refused to participate in further functional studies after the initial one: one patient had classical clinical PCD, extremely low $\mathrm{nNO}$ and classical abnormal EM; the other had classical clinical PCD and an abnormal EM and very low $\mathrm{nNO}$. In addition, the latter had a brother with PCD with identical EM presentation and immotile cilia on functional studies. Demographic and diagnostic characteristics are shown in table 1.

Lung function results are summarised in table 2. Mean (SD) absolute values of MBW variables in patients with PCD were all markedly abnormal compared with normal reference values: $\mathrm{LCI}=9.48(2.20)$ vs $6.33(0.43), \mathrm{ULN}=7.17 ; \mathrm{S}_{\text {cond }}=0.076(0.024)$ vs $0.018(0.006), \mathrm{ULN}=0.030$; and $\mathrm{S}_{\mathrm{acin}}=0.236(0.115)$ vs 0.086 $(0.025), \mathrm{ULN}=0.135$. LCI was above the ULN in $84 \%$ of patients $(23 / 27)$, while $96 \%(22 / 23)$ and $78 \%(18 / 23)$ had abnormal $S_{\text {cond }}$ and $\mathrm{S}_{\text {acin }}$, respectively.

The relationships between LCI and the $\mathrm{Sn}_{\text {III }}$ indices $S_{\text {acin }}$ and $\mathrm{S}_{\text {cond }}$ are shown in figure $1 \mathrm{~A}$ and $\mathrm{B}$. LCI correlated to $\mathrm{S}_{\text {acin }}$ $\left(R^{2}=0.45 ; p<0.001\right)$ but not to $S_{\text {cond }}$. $S_{\text {cond }}$ peaked at an LCI of about $10 \mathrm{z}$-scores, subsequently decreasing with increase in disease severity (as measured by LCI). $S_{\text {acin }}$ and $S_{\text {cond }}$ did not correlate (figure E1 in online supplement).

Mean values of spirometry parameters across the cohort were within or close to normal limits; $52 \%$ (14/27) had abnormal $\mathrm{FEV}_{1}$ and $15 \%$ (4/27) had abnormal FVC.

LCI did not show a statistically significant correlation with either $\mathrm{FEV}_{1}$ or FVC. LCI, $\mathrm{S}_{\text {cond }}$ and $\mathrm{S}_{\text {acin }}$ were abnormal in $81 \%$ $(13 / 16), 93 \%(13 / 14)$ and $79 \%(11 / 14)$, respectively, among the $13 / 27$ patients with normal $\mathrm{FEV}_{1}$ (figure $2 \mathrm{~A}-\mathrm{C}$ ). Normal LCI excluded the presence of abnormal $\mathrm{FEV}_{1}$, with the exception of a marginally reduced $\mathrm{FEV}_{1}(-2.1 \mathrm{z}$-scores) in one patient. In addition, this patient had $S_{\text {acin }}$ within the normal range while $\mathrm{S}_{\text {cond }}$ was elevated at more than 10 z-scores. When relating $S_{\text {III }}$ indices to spirometry parameters, neither $\mathrm{S}_{\text {acin }}$ nor $\mathrm{S}_{\text {cond }}$ correlated with $\mathrm{FEV}_{1}$ or FVC.

The inclusion of spirometry results performed for two patients on a different date from the MBW did not have any effect on the statistical analysis with regard to $\mathrm{FEV}_{1}$ and FVC. Correlations between lung function parameters are summarised in table $\mathrm{E} 1$ in the online supplement. 
Table 1 Demographic and diagnostic characteristics of study population

\begin{tabular}{|c|c|}
\hline \multicolumn{2}{|l|}{ Demographics } \\
\hline Number & 27 \\
\hline Female/male (n) & $17 / 10$ \\
\hline Age, years & $11.3(6.3-18.5)$ \\
\hline Age at diagnosis, years & $2.2(0.04-9.8)$ \\
\hline Weight, kg & $36.5(16.1-61.6)$ \\
\hline Height, cm & $145(114-182)$ \\
\hline \multicolumn{2}{|l|}{ Bacterial colonisation $(\mathrm{n})$} \\
\hline Chronic: $P$ aeruginosa & 1 \\
\hline Intermittent: $P$ aeruginosa & 2 \\
\hline Intermittent: $A$ xylosoxidans & 1 \\
\hline \multicolumn{2}{|l|}{ Diagnostic tests (n) } \\
\hline Typical clinical symptoms & 27 \\
\hline Nasal nitric oxide performed & 26 \\
\hline Low level & 26 \\
\hline Ciliary beat pattern and frequency analysis performed & 27 \\
\hline Normal frequency, asynchrony & $6^{*}$ \\
\hline Low frequency, asynchrony & $10^{*}$ \\
\hline Immotility & $10^{*}$ \\
\hline Normal & $1^{*}$ \\
\hline Inconclusive & $2^{*}$ \\
\hline Electron microscopy performed & 21 \\
\hline \multicolumn{2}{|l|}{ Ultrastructural defect } \\
\hline Outer dynein arm (ODA) & 6 \\
\hline Inner dynein arm (IDA) & 1 \\
\hline $\mathrm{ODA}+\mathrm{IDA}$ & 2 \\
\hline Radial spoke defect + IDA & 5 \\
\hline Transposition defect & 1 \\
\hline Periphery microtubuli defect & 5 \\
\hline Normal & 1 \\
\hline
\end{tabular}

Demographic data were not normally distributed so are presented as median (range). Diagnostic characteristics are presented as $\mathrm{n}$.

${ }^{*}$ Sum $>25$ as each patient can have more than one functional abnormality.

There was no significant correlation between any of the lung function parameters and age or age at diagnosis, respectively. Table E2 in the online supplement shows correlations between $\mathrm{MBW}$ indices and age and age at diagnosis.

Comparisons between MBW parameters and $\mathrm{FEF}_{25-75}$ and $\mathrm{FEV}_{1} / \mathrm{FVC}$ ratio are given in the online supplement.

\section{DISCUSSION}

This is the first report presenting data from MBW findings in a cohort of well-characterised children and adolescents with PCD. We found that MBW was more frequently abnormal than $\mathrm{FEV}_{1}$, the currently accepted spirometry surrogate marker of

Table 2 Spirometry and multiple breath inert gas washout (MBW) measurements

\begin{tabular}{ll}
\hline Parameter & Mean (SD) z-scores \\
\hline $\mathrm{FEV}_{1}(\mathrm{n}=27)^{*}$ & $-1.59(1.44)$ \\
$\mathrm{FVC}_{(\mathrm{n}=27)^{*}}$ & $-0.71(1.36)$ \\
$\mathrm{FEF}_{25-75}(\mathrm{n}=27)^{*}$ & $-2.11(1.39)$ \\
$\mathrm{FEV}_{1} / \mathrm{FVC}$ ratio $(\mathrm{n}=27)^{*}$ & $-1.40(1.08)$ \\
$\mathrm{LCl}_{(\mathrm{n}=27) \dagger}$ & $7.58(5.57)$ \\
$\mathrm{S}_{\text {cond }}(\mathrm{n}=23) \dagger$ & $9.64(4.08)$ \\
$\mathrm{S}_{\text {acin }}(\mathrm{n}=23) \dagger$ & $5.99(4.60)$ \\
$\mathrm{FRC}_{\text {SF6, }} \mathrm{ml}(\mathrm{n}=27)$ & $1649(603)$
\end{tabular}

${ }^{*}$ Spirometry parameters calculated using the British growth reference charts.

†MBW z-scores calculated using Swedish normative data.

$\mathrm{FEV}_{1}$, forced expiratory volume in $1 \mathrm{~s}$; FRC, functional residual capacity; $\mathrm{FVC}$, forced vital capacity; $\mathrm{FEF}_{25-75}$, forced expiratory flow at $25-75 \%$ of $\mathrm{FVC}$; $\mathrm{LCl}$, lung clearance index; $\mathrm{S}_{\text {cond }}$ and $\mathrm{S}_{\text {acin }}$ normalised phase III slope indices (see text for explanation).
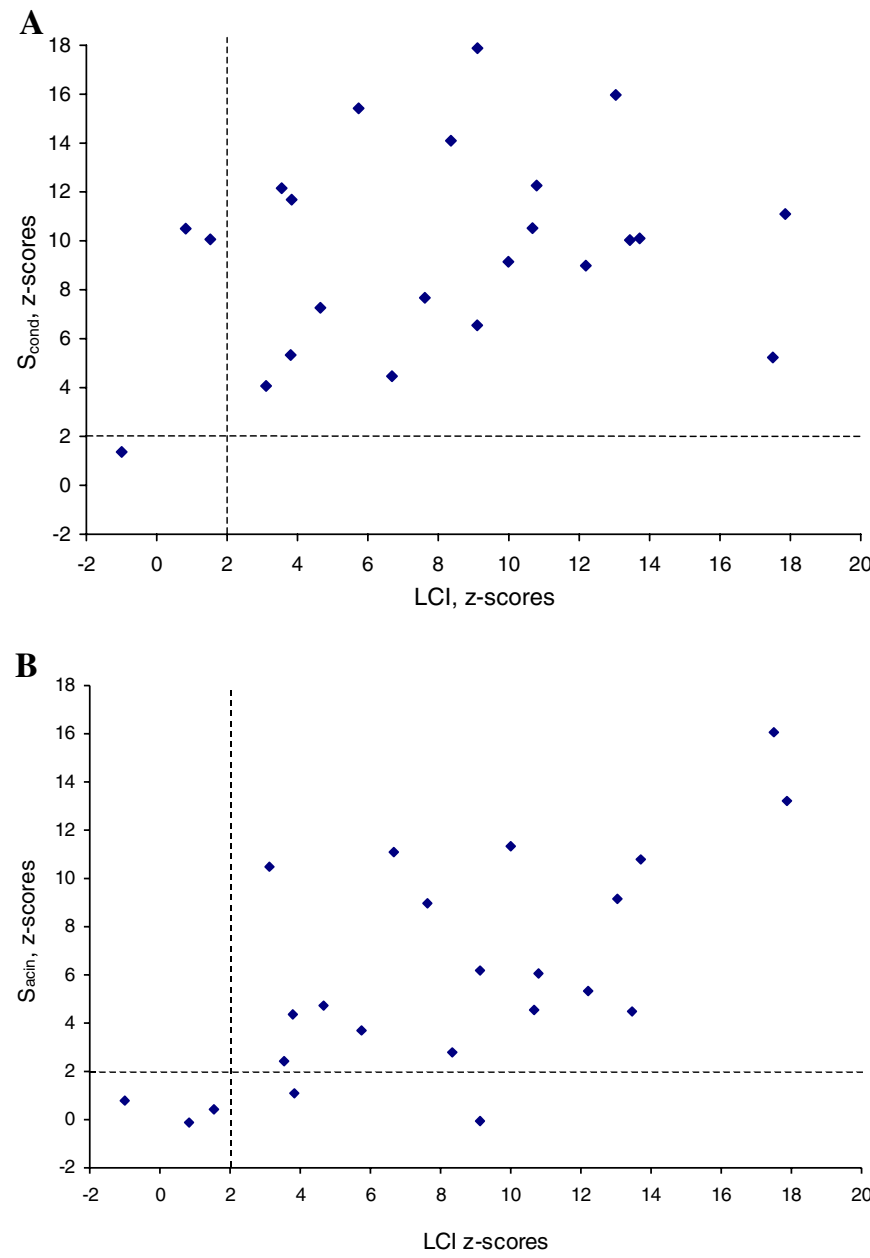

Figure 1 (A) $\mathrm{S}_{\text {cond }}$ and (B) $\mathrm{S}_{\text {acin }}$ versus $\mathrm{LCl}$ z-scores in 23 patients with primary ciliary dyskinesia. The dashed horizontal lines denote the upper limits of normality for $\mathrm{LCl}$ (mean plus $1.96 \mathrm{SD}$ ) and the dashed vertical lines denote the upper limits of normality (mean plus $1.96 \mathrm{SD}$ ) for $\mathrm{S}_{\text {acin }}$ and $S_{\text {cond, }}$ respectively. $\mathrm{LCl}$, lung clearance index; $S_{\text {cond }}$ and $S_{\text {acin, }}$ normalised phase III slope indices (see text for explanation).

disease severity. Abnormal LCI was found in nearly all patients, including those with normal $\mathrm{FEV}_{1}$. Additionally, $\mathrm{S}_{\text {cond }}$ was abnormal in all but one patient and $S_{\text {acin }}$ in more than threequarters of the patients, implying involvement of small airways even beyond the conducting airway zone. MBW parameters did not correlate with $\mathrm{FEV}_{1}$ or FVC. Measures of spirometry were on average all within or close to normal values and half the patients had normal $\mathrm{FEV}_{1}$, while the indices of VI were considerably elevated. Our findings show that PCD lung disease is characterised by marked peripheral dysfunction which, in most cases, is not detectable by spirometry.

The results of this study are consistent with previous publications showing that $\mathrm{MBW}$ is more sensitive than spirometry in detecting pulmonary diseases such as CF. ${ }^{9} 12 \quad 1324 \quad 25$ To our knowledge, the only other information to date on MBW data in PCD is an abstract by Ives et al who investigated adult patients with PCD, thus making direct comparison with our study difficult. $^{26}$

In a recent large longitudinal study in the Danish PCD cohort published from our centre ${ }^{4}$ we found a high degree of variation in the course of lung function after diagnosis. This variation could not be linked to age or to the level of lung function (ie, spirometry findings) at the time of diagnosis, with the 

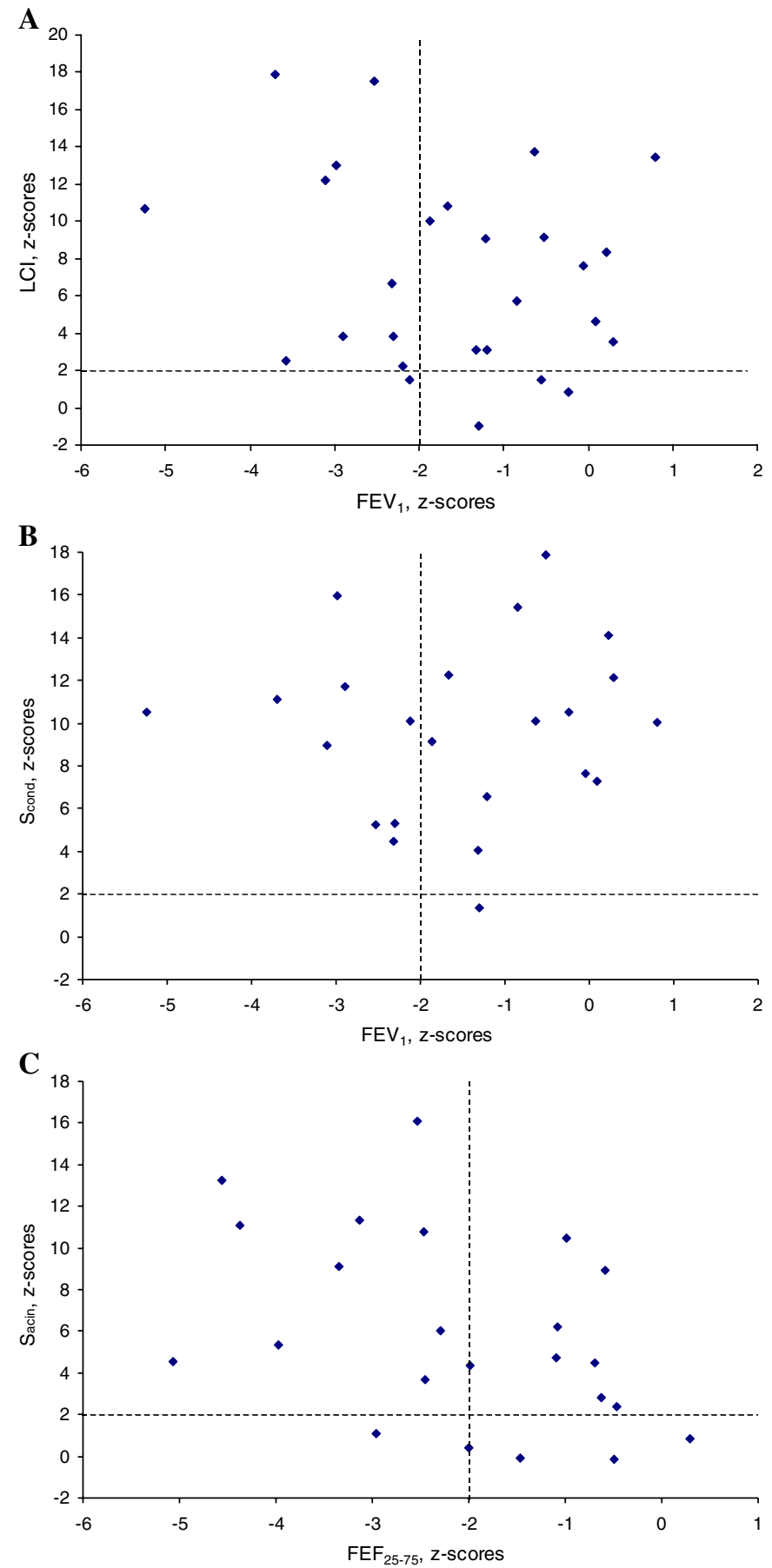

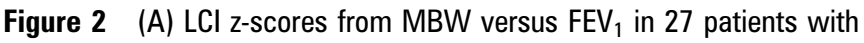
primary ciliary dyskinesia (PCD). (B) $S_{\text {cond }}$ and (C) $S_{\text {acin }}$ from MBW versus FEV $_{1}$ z-scores in 23 patients with PCD. The dashed horizontal lines denote the upper limits of normality for lung clearance index, $S_{\text {cond }}$ and $S_{\text {acin }}$ (mean plus $1.96 \mathrm{SD}$ ) and the dashed vertical lines denote the lower limits of normality (mean minus $1.96 \mathrm{SD}$ ) for $\mathrm{FEV}_{1}$. FEV $\mathrm{FE}_{1}$, forced expiratory volume in $1 \mathrm{~s}$; $\mathrm{LCl}$, lung clearance index; MBW, multiple breath inert gas washout; $S_{\text {cond }}$ and $S_{\text {acin, }}$ normalised phase III slope indices (see text for explanation).

conclusion that early diagnosis and initiated treatment, even in a tertiary centre, does not protect against decline in lung function. ${ }^{4}$ This is in line with the current study where we did not find any relationship between the degree of VI and age at diagnosis of PCD. Possible explanations are that (1) our current monitoring and management of patients with PCD is based on extrapolation of CF care which may not be sufficient; and (2) changes in spirometry values are unable to detect early lung damage as implied by our study. The latter may cause a delay in intensification of treatment when needed.

Results from studies in children and adults with CF suggest that $\mathrm{Sn}_{\text {III }}$ analysis is of limited use in more advanced disease. ${ }^{27}$ Consistent with this view, we found $S_{\text {cond }}$ to be markedly elevated even in patients with mild disease, as indicated by LCI or spirometry. In our cross-sectional analysis, $\mathrm{S}_{\text {cond }}$ reached a plateau and then declined with higher LCI. $S_{\text {cond }}$ results from differences in specific ventilation and sequential filling and emptying among lung regions sharing branch points in the conducting airway zone. This index thus reflects the "patchiness' of disease distribution. With increasing disease severity, ventilation of already poorly ventilated lung units will come to an end and inter-regional differences in ventilation nonuniformity will not increase additionally. At the same time, it could be speculated that disease progression in a distal direction and the movement of the diffusion front in a proximal direction will lead to further elevated $S_{\text {acin }}$. As expected, $S_{\text {acin }}$ was more closely associated with LCI in advanced disease. In severe disease, spirometric lung volumes and forced expiratory flows are also markedly reduced due to gas trapping and because poorly ventilated regions can no longer be compensated for by increased flow through non-flow-limited distal airways. $^{28}$

Despite abnormal $\mathrm{FEV}_{1}$, one patient presented with normal LCI and $S_{\text {acin }}$ but with highly elevated $S_{\text {cond. }}$ In children with asthma, Gustafsson ${ }^{29}$ has previously shown a more profound involvement of the small conductive airways, represented by markedly elevated $\mathrm{S}_{\text {cond, }}$, in comparison with the other VI indices. In asthma, $\mathrm{S}_{\text {cond }}$ is thus a more sensitive $\mathrm{MBW}$ index than LCI. The present finding could therefore be due to the presence of underlying (undiagnosed) asthma. Further studies in patients with PCD assessing bronchodilator response are consequently warranted. However, we believe that raised $\mathrm{S}_{\text {cond }}$ reflects a similar patchiness of disease distribution among lung units as in asthma. The finding of markedly abnormal $S_{\text {acin }}$ values in the majority of the patients with PCD suggests that PCD airway disease generally involves more peripherally located airway generations than asthma and that, in this respect, PCD resembles CF more than asthma.

In our study three patients did not have a conclusive abnormal ciliary beat pattern and frequency. Ciliary beat pattern and frequency and EM analysis play a key role in diagnosis, but PCD is likely to include a small number of phenotypes that may be manifested by subtle or no apparent structural defects and ciliary dysfunction. Consequently, studies have documented the occurrence of normal ciliary structure ${ }^{30-32}$ and function ${ }^{30}$ in patients with verified PCD. All three patients had abnormal $\mathrm{MBW}$ parameters while $\mathrm{FEV}_{1}$ and $\mathrm{FVC}$ were within the normal range (see table E3 in online supplement).

\section{Limitations of the study}

One limitation of our study is the lack of Danish MBW reference material. Instead, we used Swedish normative data as reference which were obtained using exactly the same equipment, software and procedures. In addition, the authors performing and calculating MBW tests have undergone training and have been under continual supervision by the Swedish laboratory in order to affirm the quality of the measurements.

$\mathrm{MBW}$ changes in PCD might reflect retained mucus in the airways resulting in VI. If so, $\mathrm{MBW}$ measures could improve following coughing, airway clearance manoeuvres or aerobic 
exercise. This study would be strengthened with additional information about variability in MBW measures in PCD, such as day-to-day variability, morning versus afternoon variability, before and after controlled coughs or before and after airway clearance manoeuvre. Furthers studies on these important methodological aspects are needed.

Abnormalities of peripheral airway function might reflect potentially reversible PCD lung pathology. Owing to their sensitivity to peripheral airway dysfunction, MBW tests have the potential to be used to signal the need for and to monitor the effects of early intervention and more aggressive treatment with the aim of preventing irreversible lung damage. As PCD is associated with a progressive and continuous impact on both physical and mental health, ${ }^{33}$ identification of children with early lung damage could lead to earlier and more aggressive intervention and, consequently, a better prognosis and quality of life over time.

In conclusion, our study demonstrates for the first time that MBW measures of peripheral airway function are abnormal in young patients with PCD, being far more frequent findings than abnormal spirometry. The study shows that PCD lung disease is characterised by marked peripheral dysfunction and that MBW is a promising and feasible method for early detection of airway disease in PCD. Further prospective controlled longitudinal studies assessing the utility of MBW in the management of PCD and their importance for long-term outcome are warranted.

Acknowledgements The authors thank members of the staff at the Danish PCD Center and Pediatric Pulmonary Service at Copenhagen University Hospital and the families who participated in the study.

Funding This study has been funded by The John and Birthe Meyer Foundation, Queen Louise Children's Hospital Research Trust and Aase and Ejnar Danielsen Foundation.

\section{Competing interests None}

Ethics approval Ethics approval was provided by the Danish National Committee on Biomedical Research Ethics.

Contributors All authors contributed to aspects of study design, data collection, data interpretation and manuscript review.

Provenance and peer review Not commissioned; externally peer reviewed.

\section{REFERENCES}

1. Barbato A, Frischer T, Kuehni CE, et al. Primary ciliary dyskinesia: a consensus statement on diagnostic and treatment approaches in children. Eur Respir $J$ 2009;34:1264-76.

2. O'Callaghan C, Chilvers $\mathrm{M}$, Hogg $\mathrm{C}$, et al. Diagnosing primary ciliary dyskinesia. Thorax 2007;:62:656-7.

3. Noone PG, Leigh MW, Sannuti A, et al. Primary ciliary dyskinesia: diagnostic and phenotypic features. Am J Respir Crit Care Med 2004;169:459-67.

4. Marthin JK, Petersen N, Skovgaard LT, et al. Lung function in patients with primary ciliary dyskinesia: a cross-sectional and 3-decade longitudinal study. Am J Respir Crit Care Med 2010:181:1262-8.

5. Brown DE, Pittman JE, Leigh MW, et al. Early lung disease in young children with primary ciliary dyskinesia. Pediatr Pulmonol 2008:43:514-16.

6. Leigh MW. Primary ciliary dyskinesia. Semin Respir Crit Care Med 2003;24:653-62.
7. Santamaria F, Montella S, Tiddens HA, et al. Structural and functional lung disease in primary ciliary dyskinesia. Chest 2008;134:351-7.

8. Tiddens HA, Donaldson $\mathrm{SH}$, Rosenfeld $\mathrm{M}$, et al. Cystic fibrosis lung disease starts in the small airways: can we treat it more effectively? Pediatr Pulmonol 2010;45:107-17

9. Aurora P, Bush A, Gustafsson P, et al. Multiple-breath washout as a marker of lung disease in preschool children with cystic fibrosis. Am J Respir Crit Care Med 2005; 171:249-56.

10. Aurora P, Stanojevic S, Wade A, et al. Lung clearance index at 4 years predicts subsequent lung function in children with cystic fibrosis. Am J Respir Crit Care Med 2011; 183:752-8

11. Brody AS, Klein JS, Molina PL, et al. High-resolution computed tomography in young patients with cystic fibrosis: distribution of abnormalities and correlation with pulmonary function tests. J Pediatr 2004;145:32-8.

12. Gustafsson PM, De Jong PA, Tiddens HA, et al. Multiple-breath inert gas washout and spirometry versus structural lung disease in cystic fibrosis. Thorax 2008;63:129-34.

13. Gustafsson PM, Aurora P, Lindblad A. Evaluation of ventilation maldistribution as an early indicator of lung disease in children with cystic fibrosis. Eur Respir $J$ 2003;22:972-9.

14. Verbanck S, Schuermans D, Van MA, et al. Conductive and acinar lung-zone contributions to ventilation inhomogeneity in COPD. Am J Respir Crit Care Med 1998:157:1573-7.

15. Green K, Buchvald F, Marthin JK, et al. Lung clearance index in children with primary ciliary dyskinesia. Am J Respir Crit Care Med 2010;181:A6723.

16. Bush A, Chodhari R, Collins N, et al. Primary ciliary dyskinesia: current state of the art. Arch Dis Child 2007;:92:1136-40.

17. Hogg C. Primary ciliary dyskinesia: when to suspect the diagnosis and how to confirm it. Paediatr Respir Rev 2009;10:44-50.

18. Marthin JK, Nielsen KG. Choice of nasal nitric oxide technique as first-line test for primary ciliary dyskinesia. Eur Respir J 2011;37:559-65.

19. Aurora P, Gustafsson P, Bush A, et al. Multiple breath inert gas washout as a measure of ventilation distribution in children with cystic fibrosis. Thorax 2004:59:1068-73.

20. Robinson PD, Goldman MD, Gustafsson PM. Inert gas washout: theoretical background and clinical utility in respiratory disease. Respiration 2009;78:339-55.

21. Anon. Standardization of spirometry, 1994 update. American Thoracic Society. Am J Respir Crit Care Med 1995;152:1107-36

22. Stanojevic $\mathbf{S}$, Wade A, Stocks J, et al. Reference ranges for spirometry across all ages: a new approach. Am J Respir Crit Care Med 2008;177:253-60.

23. Marthin JK, Mortensen J, Pressler T, et al. Pulmonary radioaerosol mucociliary clearance in diagnosis of primary ciliary dyskinesia. Chest 2007:132:966-76.

24. Kraemer R, Blum A, Schibler A, et al. Ventilation inhomogeneities in relation to standard lung function in patients with cystic fibrosis. Am J Respir Crit Care Med 2005;171:371-8.

25. Lum S, Gustafsson $\mathrm{P}$, Ljungberg $\mathrm{H}$, et al. Early detection of cystic fibrosis lung disease: multiple-breath washout versus raised volume tests. Thorax 2007:62:341-7.

26. Ives A, Irving $S$, Hogg $C$, et al. Lung clearance index and structural lung disease in cystic fibrosis: a comparison with primary ciliary dyskinesia. Pediatr Pulmonol 2010;45:361-2.

27. Horsley AR, Macleod KA, Robson AG, et al. Effects of cystic fibrosis lung disease on gas mixing indices derived from alveolar slope analysis. Respir Physiol Neurobiol 2008;162:197-203

28. McNamara JJ, Castile RG, Glass GM, et al. Heterogeneous lung emptying during forced expiration. J Appl Physiol 1987;63:1648-57

29. Gustafsson PM. Peripheral airway involvement in CF and asthma compared by iner gas washout. Pediatr Pulmonol 2007:42:168-76.

30. Jorissen $\mathbf{M}$, Willems $\mathbf{T}$, Van der Schueren B. Ciliary function analysis for the diagnosis of primary ciliary dyskinesia: advantages of ciliogenesis in culture. Acta Otolaryngol 2000:120:291-5.

31. Rutman A, Cullinan $P$, Woodhead $M$, et al. Ciliary disorientation: a possible variant of primary ciliary dyskinesia. Thorax 1993;48:770-1.

32. Biggart $\mathbf{E}$, Pritchard $\mathrm{K}$, Wilson $\mathrm{R}$, et al. Primary ciliary dyskinesia syndrome associated with abnormal ciliary orientation in infants. Eur Respir J 2001;17:444-8.

33. Pifferi M, Bush A, Di CM, et al. Health-related quality of life and unmet needs in patients with primary ciliary dyskinesia. Eur Respir J 2009:35:787-94. 